\title{
S sciendo \\ A COMPUTERIZED TOOL FOR EDUCATION AND TRAINING ON ERGONOMIC RISK EVALUATION
}

doi:10.2478/mape-2018-0096

Date of submission of the article to the Editor: 04/2018

Date of acceptance of the article by the Editor: 07/2018

MAPE 2018, volume 1, issue 1, pp. 759-765

\author{
Dr Eng. Andrzej Marek Lasota \\ Prof. Eunika Baron-Polańczyk \\ University of Zielona Gora, Poland
}

\begin{abstract}
In the light of the challenges of the Industry 4.0 the weight of safety and health, and ergonomics are rising. Nowadays one of the common problem in industry are work-related musculoskeletal disorders (WRMSDs). Therefore, an ergonomic risk evaluation is crucial as well the knowledge and education in this area. This paper presents a computerized tool for ergonomic education on ergonomic risk evaluation at the workplace. The tool based on quick exposure check pen and paper technique and Excel spreadsheet environment. It is easy to use and assists students in the evaluation of real as well of simulated workplaces. The proposed tool includes a few integrated parts: background description, students - observer's and worker's evaluation and results with visual interpretation. The preliminary evaluation of the Excel tool was carried out by students. It showed that it is useful and easy in use. And the students' opinions on the computerized tool for ergonomic risk evaluation are very encouraging and promise what was presented in this study.
\end{abstract}

Keywords: ergonomics, QEC, risk, training, education

\section{INTRODUCTION}

Production systems are defined as a complex system of physical elements such as machinery and equipment, tools and people. Employees in the manufacturing system are "internal consumers" and the system must be designed to meet their needs. At the same time, the production system must produce goods that meet the needs of "external consumers". In terms of ergonomics and health and safety, the production system is designed to meet the needs of both internal and external consumers (Lasota and Hankiewicz, 2016). Moreover, people are part of engineered system and they play different role of whole of the life-cycle of it. Workers are involved in the production, assembly, transport, installation, use, maintenance and disassembly of all designed systems (Tytyk, 2001). Although the role of Human Factors/Ergonomics (HFEs) is growing in industry. And the International Ergonomics Association defined HFEs as "the scientific discipline concerned with the understanding of interactions among humans and other elements of a system, and the profession that applies theory, principles, data and methods to design in order to optimize human well-being and overall system performance". Therefore, practitioners, engineers should contribute HFEs to the design and evaluation of jobs, tasks, products, environments and systems in order to make them compatible with the needs, abilities and limitations of people (IEA, 2018; Butlewski, 2014).

Also, production systems dependent on the human operator are particularly prone to problems related to disorders, maintaining production quality and productivity. Because the job performed by the employee is accompanied by a physical workload, which involves ergonomic risk. And several factors have an impact on workload, such as: workstation's layout, job and task design, working methods, tools and their design and the anthropometric characteristics of workers (Lasota and Hankiewicz, 2017a; Czernecka and Górny, 2018). 
HFEs play an important role in production due to the increasing conditions of competition on the global market. To ensure increase productivity, employees' well-being and ergonomic risk factors need to be properly assessed and should be at an acceptable ergo-level. Poor workplace ergonomics causes inefficiency and lack of productivity, occupational diseases and health injuries of employees. They are as $s$ a result of work or/and working conditions and working environment. Therefore, it is important to identify ergonomics risk before workers develop work-related musculoskeletal disorders (WRMSDs), because disorders can result in decreased quality of work, productivity and increased cost and absenteeism (Dunning et al., 2010; BLS, 2016; HSE, 2018; ZUS, 2017).

Nowadays musculoskeletal disorders are affected more than 100 million Europeans (Lidgren et al., 2014). And, in the European Union, on work-related health problem experienced 20 million workers in the past 12 months and 80 million workers are exposed to factors that can adversely affect physical health. This is financial burden and the costs of all absences have been estimated amount from $2.1 \%$ to $3.1 \%$ of the gross domestic product in the European Union (Schneider and Irastorza, 2010 ). In the Great Britain, in 2016/2017 WRMSDs accounted $39 \%$ of all work related illnesses and it is estimated 8.9 million working days were lost due to WRMSDs what represent $35 \%$ of all days lost due to work related ill health (HSE 2018). In Poland, diseases of musculoskeletal system are the second most frequent cause of absence from work due to sickness. And in 2016 they were the reason for over 36 million days of absence, accounting for $15.3 \%$ of all absences (ZUS, 2017).

Scientists have developed a wide range of methods to estimate the workload on the employee related to WRMSDs. And number of them are observational techniques used to evaluate an ergonomic risk to WRMSDs: Ovako Working Posture Analysing System, Rapid Upper Limb Assessment, Rapid Entire Body Assessment, Quick Exposure Check, etc. (Takala et al., 2010). And they are widely used in various industry sectors (Lu et al., 2016; Lasota and Hankiewicz, 2017b; Hanson et al., 2018).

From the safety and ergonomic viewpoint, the key elements in the production process affecting workers and their efficient workflow are excessive load, improper posture at work, etc. (Górny, 2014). The resulting disturbances in the human system can lead to problems with maintaining production, quality and an increase in costs associated with sickness and absence caused by the negative impact of work on employee health (Dunning et al., 2010; BLS, 2016; HSE, 2018; ZUS, 2017). Linking ergonomics in production system is therefore important if not crucial. Furthermore, mentioned aspects becomes more challenging in the light of the current developments such as Industry 4.0. Therefore preventing of WRMSDs is essential. One of the key method of prevention is education and training. Hence, the key element is teaching students as future engineers, practitioners designing production systems as well as those who deal with work environments. And further training of specialists already working in industry. Therefore, the purpose of this study is to present an computerized tool, developed to teach students, practitioners of ergonomic risk assessment techniques.

\section{MATERIALS AND METHODS}

The computer program is based on the Excel worksheet environment and Visual Basic for Application (VBA). The implemented evaluation method based on a pen and paper Quick Exposure Check (QEC) technique and has been developed using the Excel worksheet and VBA. The QEC method is a techniques developed for practitioners in order to investigate musculoskeletal risk factors among workers and conduct evaluation of a workplace to facilitate redesign (David et al., 2008). The technique involves an evaluation of the back, shoulder/arm, wrist/hand, and neck body segments regarding their position and repetitive movement. In addition, QEC takes into account the subjective exposure of employees in relation to: task duration, maximum weight handled, hand force exertion, vibration, visual demand of the task, difficulty to keep up with the work and stressfulness of the work. The advantage of this tool is that the system of assessment takes into account the interaction between expert judgment 
and self-assessment of the employee. The analysis of tasks using QEC gives exposure scores to body parts and additional factors. The exposure levels for back, shoulder/arm, wrist/hand and neck are categorized into four exposure categories: low, moderate, high and very high. The overall exposure level $E$ is then calculated as a percentage rate between the actual total exposure score for body segments and the maximum possible total value.

Preliminary action levels for the QEC are classified according to four levels of risk: low, medium, high and very high. Low risk indicates acceptable musculoskeletal load. Medium risk indicates further investigation is needed and changes may be required. High risk - an investigation and changes are required soon; and very high risk - immediate investigation and changes are required.

\section{RESULTS AND DISCUTION}

The Excel-based tool (Fig. 1.) consists of two main logic parts:

- Evaluation - starting to evaluate exposure to WRMSDs in the workplace and includes: Background information \& task description (basic information: department, workplace, task description, etc.), Observer's evaluation (body segments: back, shoulder/arm, wrist/hand, neck posture evaluation, their position, movement and repetition), Worker's evaluation (evaluation of weigh handled manually, force level, time spent with task, visual demand, vibration, pace, stress).

- Report, which includes: Exposure score (diagram of detailed results for interaction between factors e.g. back posture \& weight handled manually - score calculated by VBA functions; final score for all body segments and additional factors) and Results and interpretation of evaluated task (table with exposure score and exposure risk, chart with graphical interpretation and human body map risk visualization). Results collection according evaluated tasks at assembly line, production line.

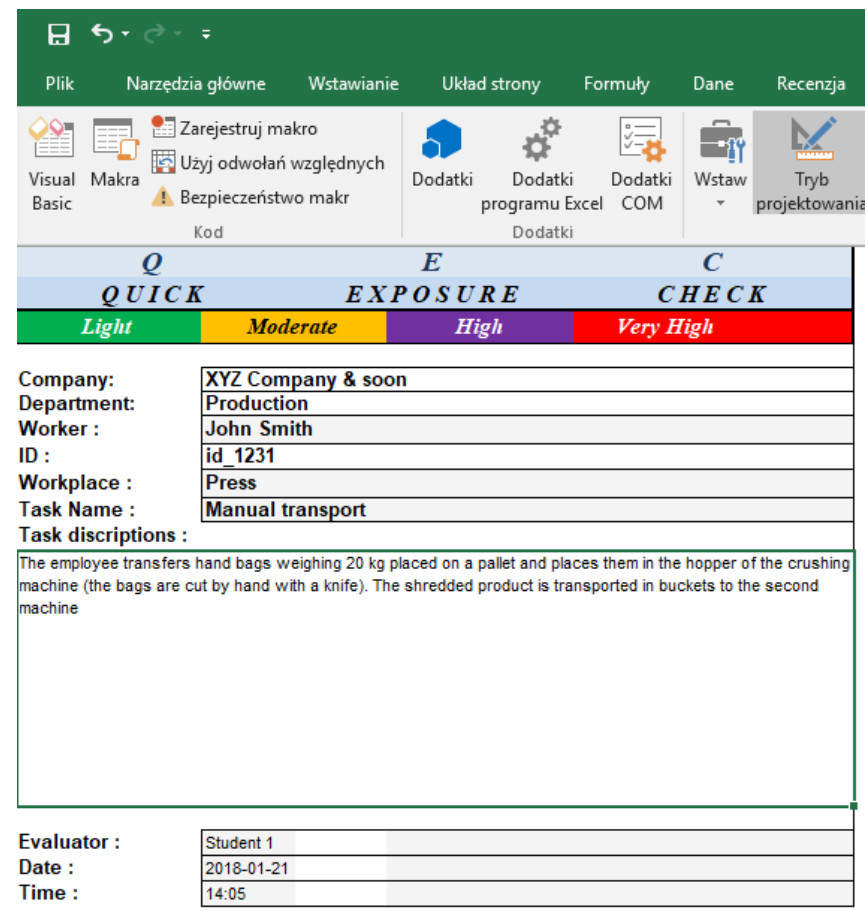

Fig. 1. The QEC Excel-based tool

In QEC spreadsheet mentioned parts were implemented on separate sheet. On the Background information \& task descriptions students inserting fundamental data such as; company name, workplace, worker's name, task name, etc. (Fig. 1.). The core evaluation starting from the sheet - Observer's Evaluation (Fig. 2.). 


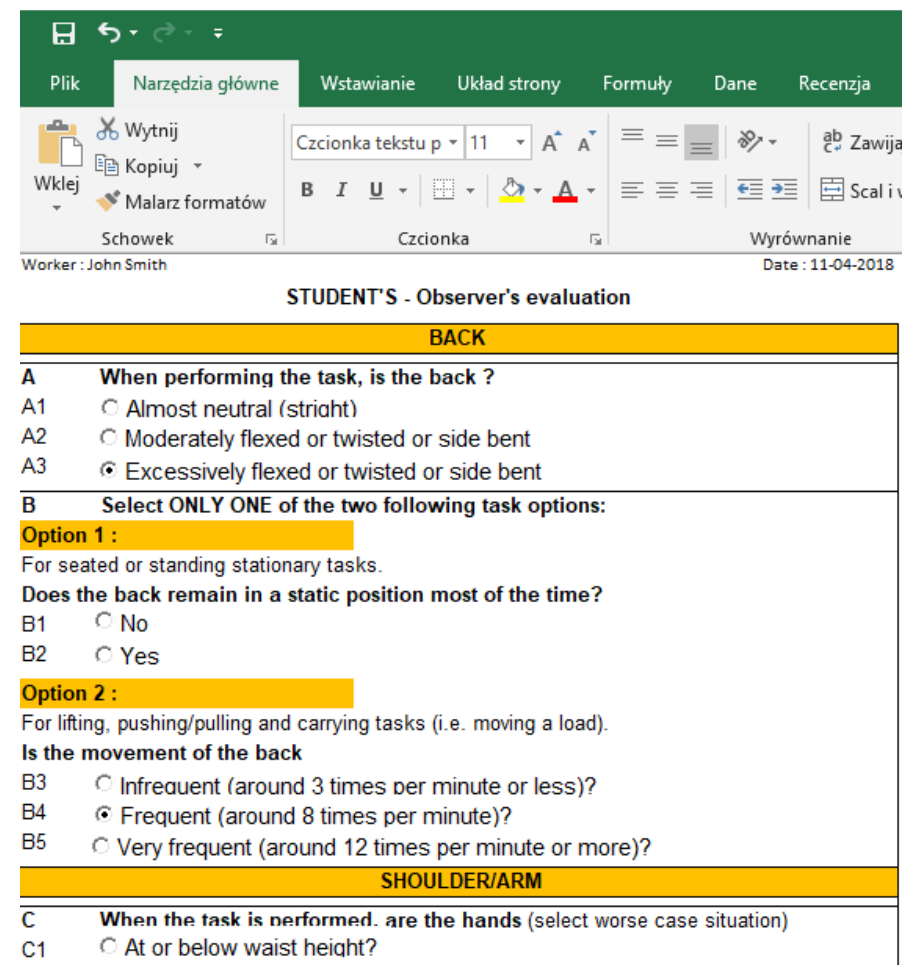

Fig. 2. Student's - observer's evaluation sheet

Student is required to choose an option from the available fields for each domain. For example for back posture, the student have to choose from domain back posture one of three options: A1 - almost neutral; A2 - moderately flexed or twisted or side bent; A3 - excessively flexed or twisted or side bent by clicking on an option button. The second step of assessment is Worker's evaluation. Student is required only to choose an option from the available fields for each domain, by clicking on an option button.

On the next stage implemented VBA functions automatically take into account interactions between chosen variables and calculating results then putting them into exposure score sheet and results' sheets. Students can show and analyse interaction between assessed factors and results between ergonomics risk indicators at the QEC Exposure score sheet; for example, for Back domain - Back Posture $(A)$ \& Weight $(H)$. The summarized results of body segments and additional risk factors exposure, overall exposure score $\mathrm{E}$ are presented on the Results \& visualization sheet (Fig. 3.). It used coloured scale to highlight the risk of exposure: low risk green light, medium risk - orange, high risk - pink, very high risk - red. The figure of human with body map was used to show the level of exposure in evaluated body parts.

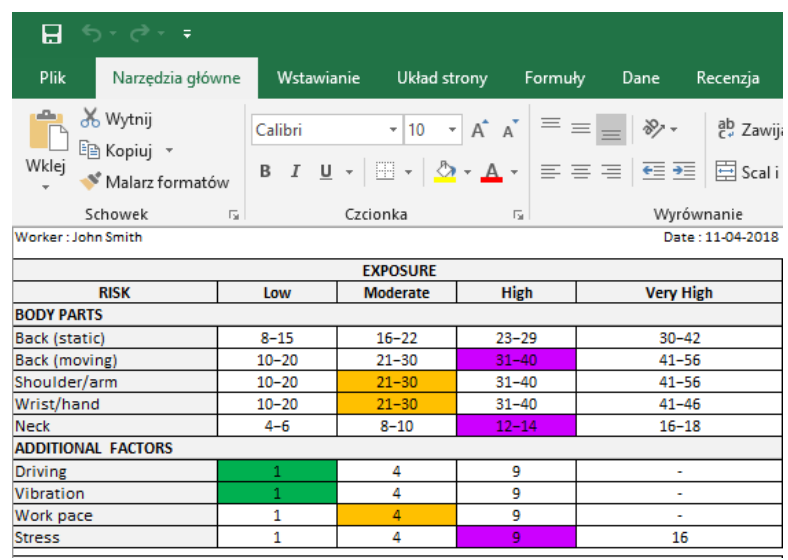

Fig. 3. Results sheet 
In general, two paths for the application of the program have been designed. One for teaching the evaluation of individual workplace, the second for teaching the evaluation of many workplaces on the assembly line or production line.

In the case of assessment stations at assembly line or production line an additional sheet called Task lists was developed. It allows to see and analyse all tasks evaluated of chosen assembly/production line. Exposure level as well Action level were highlighted by an appropriate colour of risk level (green, orange, pink, red) (Fig. 4.).

Moreover, after evaluation of task students can check how their recommendation and/or corrective actions will influence on the risk to WRMSDs. They can check different solution's scenarios by choosing the appropriate options assigned to the assessed risk factors in each domain e.g. back posture.

The preliminary evaluation of the usability of the Excel based tool was made by students. Face-to-face interview with them showed that contents of the program are presented in an easy to understand way as well the detail information included on each sheet. They emphasise that the program is well organized and helped them to learn and understand the issue of ergonomics risk evaluation. They satisfied that the program give them the attempts to check different scenarios of ergonomics intervention and finally they concluded that program is easy to use and increased their interest in ergonomics risk assessment.

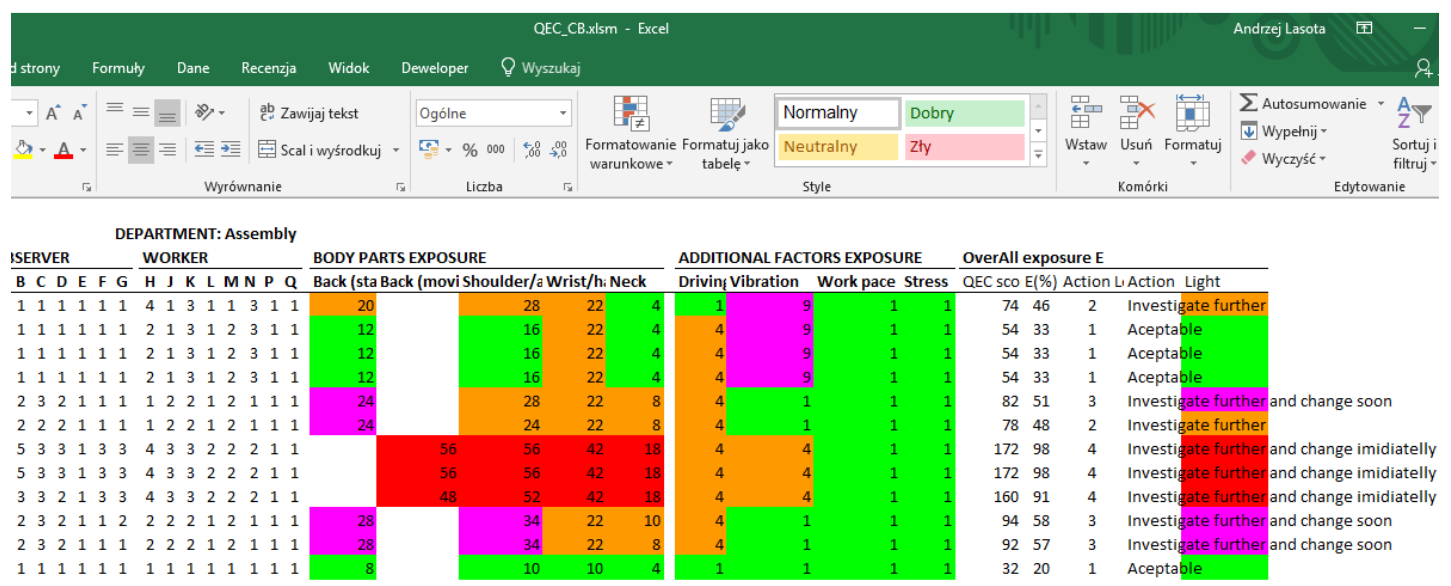

Fig. 4. Results of evaluation of stations at assembly line

Students appreciated that assessment of the different examples enable them to understand the importance of ergonomic risks more clearly. And most importantly, none of them had any problems with entering data or reading results. The students' opinions were very encouraging and promising in evaluating the Excel-based tool for ergonomic risk assessment which was presented in this study.

The use of this type of simple and useful information and communication technology (ICT) solutions (tools) corresponds to the motives behind applying and not applying ICT. According to earlier studies, some fundamental reasons why teachers use of ICT in their educational practice are: 1) ICT make their work more efficient and practical; 2) the great potential for making the processes of teaching and learning more efficient and practical; 3 ) the appreciation of ICT as a universal and practical instrument applicable to a wide array of educational incentives; 4) the holistic insight into improving and optimizing teachers' professional practice and students' learning process, as well as into appreciation of technology as a modern, universal and useful instrument, supporting diverse, professional and non-professional incentives; 5 ) the broad applicability of modern technologies in stimulating the learning process and in supporting the students' development; 6) outside conditioning, i.e. the need, compulsion, order or duty, in other words, external motivation (global requirements) (BaronPolańczyk, 2013). Thus, the above described Excel-based tool for education and training of 
ergonomic risk evaluation is a very good exemplification of the model of the learning environment because it's very well embedded in this model (Baron-Polańczyk, 2014).

\section{CONCLUSION}

In this study, an Excel-based tool for education and training of ergonomic risk evaluation was presented. This tool have several advantages. Firstly, it is a low-cost because it works in Excel environment which is very common on PC computers and it not required any additional computer application. The other feature is that the tool is easy in use and user-friendly that could be implemented by practitioners and students easily with pretty low implementation cost. The next advantage is that the Excel based tool allows to evaluate independent individual workplace as well more complex workplaces such as stations at assembly line or workplaces at production line.

Moreover, in manufacturing environment speed is very important. Due to the fast-changing manufacturing environment, also the working conditions are fast-changing. These changes require recalculations of the ergonomic risk immediately too. The proposed tool meets the needs of practitioners allows users to immediately respond to changes and educate students in this area. The final advantage of this software is that the students could try asses ergonomic risk in various ergonomic environments easily and quickly. They can check the different intervention solutions or/and they can simulate different scenarios of an ergonomic intervention. And for authors' students' feedback about the computerized tool for ergonomic risk evaluation is very useful and encouraging and promising.

\section{ACKNOWLEDGEMENTS}

The authors wish to thank the students for their cooperation and assistance in this research.

\section{REFERENCES}

Baron-Polańczyk, E. (2013). Teachers' information competence and use of ICT methods and tools Research report. The New Educational Review, 32(2), pp. 324-334.

Baron-Polańczyk, E. (2014). The model of the continuum of teachers' learning environment a cloud or a silo? The New Educational Review, 38(4), pp. 177-188.

BLS (2016). Nonfatal Occupational Injuries and Illnesses Requiring Days Away from Work, 2015. U.S. Bureau of Labor Statistics. Available at: https://www.bls.gov/news.release/osh2.toc.htm [Accessed 3 Apr. 2018].

Butlewski, M. (2014). Practical approaches in the design of everyday objects for the elderly. In: Applied Mechanics and Materials. Trans Tech Publications. vol. 657, pp. 1061-1065.

Czernecka, W. and Górny, A. (2018). Ergonomic risk measurement in prioritizing corrective actions at workstations. In: Arezes P.M. et al., ed., Occupational safety and hygiene VI, London : Taylor \& Francis Group, pp. 419.

David, G., Woods, V., Li, G. and Buckle, P. (2008). The development of the Quick Exposure Check (QEC) for assessing exposure to risk factors for work-related musculoskeletal disorders. Applied ergonomics, 39(1), 57-69.

Dunning, K. K., Davis, K. G., Cook, C., Kotowski, S. E., Hamrick, C., Jewell, G. and Lockey, J. (2010). Costs by industry and diagnosis among musculoskeletal claims in a state workers compensation system: 1999-2004. American journal of industrial medicine, 53(3), pp. 276-284.

Górny, A. (2014). Human factor and ergonomics in essential requirements for the operation of technical equipment. In: Stephanidis C., ed., International Conference on Human-Computer Interaction. Springer, Cham, pp. 449-454.

Hanson, R., Medbo, L., Berlin, C. and Hansson, J. (2018). Manual picking from flat and tilted pallet containers. International Journal of Industrial Ergonomics. 64, pp. 199-212.

HSE (2018). Work Related Musculoskeletal Disorder Statistics (WRMSDs) in Great Britain 2017, Health and Safety Executive. [online] Available at: http://www.hse.gov.uk/Statistics/causdis/musculoskeletal/msd.pdf?pdf=msd [Accessed 3 Apr. 2018].

IEA (2018). Definition and domains of ergonomics. [online] International Ergonomics Association. Available at: http://www.iea.cc/whats/ [Accessed 22 Mar. 2018].

Lasota, A.M. and Hankiewicz K. (2016). Working Postures of Spot Welding Machine Operators. In: Arezes P.M. et al., ed., Occupational safety and hygiene IV, London : Taylor \& Francis Group, pp. 261-264 
Lasota, A.M. and Hankiewicz, K. (2017a). The study of postural workload in assembly of furniture upholstery. In: MATEC Web of Conferences. [online] EDP Sciences, vol. 137, p. 07002. Available at: https://www.matecconferences.org/articles/matecconf/abs/2017/51/matecconf_mtem2017_07002/matecconf_mte m2017_07002.html [Accessed 3 Apr. 2018].

Lasota, A.M. and Hankiewicz, K. (2017b). The conceptual framework for physical risk assessment in multi-purpose workplaces. In: MATEC Web of Conferences. [online] EDP Sciences vol. 137, p. 03007. Available at: https://www.matecconferences.org/articles/matecconf/abs/2017/51/matecconf_mtem2017_03007/matecconf_mte m2017_03007.html [Accessed 3 Apr. 2018].

Lidgren, L., Gomez-Barrena, E., Duda, G. N., Puhl, W. and Carr, A. (2014). European musculoskeletal health and mobility in Horizon 2020. Setting priorities for musculoskeletal research and innovation. Bone and Joint Research, 3(3) pp. 48-50,

Lu, J. M., Twu, L. J. and Wang, M. J. J. (2016). Risk assessments of work-related musculoskeletal disorders among the TFT-LCD manufacturing operators. International Journal of Industrial Ergonomics, 52, pp. 40-51.

Schneider, E., Irastorza, X. B.and Copsey, S. (2010). OSH in figures: Work-related musculoskeletal disorders in the EU-Facts and figures. Office for Official Publications of the European Communities. [online] Available at: https://osha.europa.eu/en/tools-andpublications/publications/reports/TERO09009ENC/view. [Accessed 6 Apr. 2018].

Takala, E. P., Pehkonen, I., Forsman, M., Hansson, G. Å., Mathiassen, S. E., Neumann, W. P., Sjøgaard, G., PhD, Veiersted, K.B., Westgaard, R.H. and Winkel, J. (2010). Systematic evaluation of observational methods assessing biomechanical exposures at work. Scandinavian journal of work, environment \& health, 36(1), pp. 3-24.

Tytyk, E. (2001). Projektowanie ergonomiczne. Warszawa-Poznań: Wydawnictwo Naukowe PWN.

ZUS (2017). Absencja chorobowa w 2016 roku. Warszawa: Zakład Ubezpieczeń Społecznych. [online] Available

at: http://www.zus.pl/documents/10182/39590/Absencja+chorobowa+w+2016+roku.pdf/1475e6ca1682-42fc-ac9e-d097d32e325c?version=1.0 [Accessed 5 Apr. 2018]. 